Supporting Information (SI) for the manuscript:

\title{
Solvent-Dependent Self-Assembly of an Oxalato-Based Three-Dimensional Magnet Exhibiting a Novel Architecture
}

Marta Mon,${ }^{\dagger}$ Thais Grancha,${ }^{\dagger}$ Michel Verdaguer,${ }^{\ddagger}$ Cyrille Train,${ }^{\perp}$ Donatella Armentano*, and Emilio Pardo ${ }^{*}, \dagger$

†Departament de Química Inorgànica, Instituto de Ciencia Molecular (ICMOL), Universitat de València, 46980 Paterna, València, Spain

\#Institut Parisien de Chimie Moléculaire, Université Pierre et Marie Curie-Paris 6, UMR CNRS 8232, 75252 Paris cedex 05, France

${ }^{\perp}$ Laboratoire National des Champs Magnétiques Intenses, UPR CNRS 3228 , Université Grenoble-Alpes, B.P. 166, 38042 Grenoble cedex 9, France

§Dipartimento di Chimica e Tecnologie Chimiche, Università della Calabria, Rende 87036, Cosenza, Italy 


\section{Experimental Section}

Materials. All chemicals were of reagent grade quality. They were purchased from commercial sources and used as received. $\left[\mathrm{N}\left(\mathrm{CH}_{3}\right)_{4}\right]_{3}\left[\mathrm{Cr}(\mathrm{ox})_{3}\right] \cdot 3 \mathrm{H}_{2} \mathrm{O}$ was prepared by a previously reported method. ${ }^{1}$

[N(CH3)4 $]_{6}\left[\mathrm{Mn}_{3} \mathrm{Cr}_{4}(\mathrm{Ox})_{12}\right] \cdot \mathbf{6} \mathrm{CH}_{3} \mathrm{OH}$ (1): Well-formed large purple parallelepipeds of 1 suitable for single-crystal X-ray diffraction were obtained, in one step, by slow diffusion, in an $\mathrm{H}$-shaped tube at $16{ }^{\circ} \mathrm{C}$, of methanolic solutions containing stoichiometric amounts of the preformed $\left[\mathrm{N}\left(\mathrm{CH}_{3}\right)_{4}\right]_{3}\left[\mathrm{Cr}{ }^{\mathrm{III}}(\mathrm{ox})_{3}\right]$ on one side of the tube and $\mathrm{Mn}\left(\mathrm{NO}_{3}\right)_{2} \cdot 4 \mathrm{H}_{2} \mathrm{O}$ on the other side. The crystals were filtered on paper and airdried. Yield: 67\%; Anal. calcd (\%) for $\mathrm{C}_{54} \mathrm{H}_{96} \mathrm{Cr}_{4} \mathrm{Mn}_{3} \mathrm{~N}_{6} \mathrm{O}_{54}$ (2069): C 31.38, H 4.68, N 4.07; found: C 31.18, H 4.53, N 4.06; IR (KBr): $v=2983$ and $2939 \mathrm{~cm}^{-1}(\mathrm{C}-\mathrm{H}), 1628$ $\mathrm{cm}^{-1}(\mathrm{C}=\mathrm{O})$.

Physical Techniques. Elemental (C, H, N) analyses were performed at the Microanalytical Service of the Universitat de València. ). FT-IR spectra were recorded on a Perkin-Elmer 882 spectrophotometer as $\mathrm{KBr}$ pellets. The thermogravimetric analysis was performed on crystalline samples under a dry $\mathrm{N}_{2}$ atmosphere with a Mettler Toledo TGA/STDA $851^{\mathrm{e}}$ thermobalance operating at a heating rate of $10^{\circ} \mathrm{C}$ $\min ^{-1}$.

X-ray Powder Diffraction Measurements. A solid polycrystalline sample of $\mathbf{1}$ was introduced into a $0.5 \mathrm{~mm}$ borosilicate capillary prior to being mounted and aligned on an Empyrean PANalytical powder diffractometer, using $\mathrm{Cu} \mathrm{K \alpha}$ radiation $(\lambda=$ $1.54056 \AA$ A). For each sample, five repeated measurements were collected at room temperature $\left(2 \theta=2-50^{\circ}\right)$ and merged in a single diffractogram.

Magnetic Measurements. Variable-temperature (2.0-300 K) direct current $(d c)$ magnetic susceptibility measurements under an applied field of $100 \mathrm{G}(T<50 \mathrm{~K})$ and 1 $\mathrm{T}(T \geq 50 \mathrm{~K})$, and magnetization measurements at $2.0 \mathrm{~K}$ were carried out with a Quantum Design SQUID magnetometer. Variable-temperature $(2.0-15 \mathrm{~K})$ alternating

\footnotetext{
${ }^{1}$ Pardo, E.; Train, C.; Boubekeur, K.; Gontard, G.; Cano, J.; Lloret, F.; Nakatani, K.; Verdaguer, M. Inorg. Chem. 2012, 51 (21), 11582-11593.
} 
current (ac) magnetic susceptibility measurements at 100, 1000 and $10000 \mathrm{~Hz}$ were carried out under a zero applied static field with a Quantum Design Physical Property Measurement System (PPMS). The magnetic susceptibility data were corrected for the diamagnetism of the constituent atoms and the sample holder. $D c$ and $a c$ magnetic measurements were performed on powdered microcrystals of $\mathbf{1}$ and restraining the sample with $n$-eicosane in order to prevent any solvent loss.

X-ray crystallographic data collection and structure refinement. A suitable crystal $\left(0.22 \times 0.18 \times 0.18 \mathrm{~mm}^{3}\right)$ was selected and diffraction data were collected at room temperature on a Bruker-Nonius X8APEXII CCD area detector diffractometer using graphite-monochromated Mo-K $\mathrm{K}_{\alpha}$ radiation $(\lambda=0.71073 \AA)$. The data were processed through the $\mathrm{SAINT}^{2}$ reduction and $\mathrm{SADABS}^{3}$ multi-scan absorption software. The structure was solved with the ShelXS structure solution program, using the Direct Methods solution method. The model was refined with version 2013/4 of ShelXL against $F^{2}$ on all data by full-matrix least squares. ${ }^{4}$

A quite poor diffraction powder of the samples was observed as expected for porous three-dimensional structures containing disordered solvent molecules. In fact, a completeness of diffraction data of $100 \%$ was obtained for $\theta=22.32^{\circ}$, a value slightly lower than $25^{\circ}$ (detected as Alerts $\mathrm{A}$ in the checkcif file), even if many efforts have been made to extract the best diffraction data from the sample. However, the solution and refinement parameters are suitable thus we are convinced that the structure found is consistent.

All non-hydrogen atoms were refined anisotropically. The hydrogen atoms of the tetramethylammonium cations were set in calculated positions and refined as riding atoms. In the refinement of the structure of compound $\mathbf{1}$ was not possible to find a reasonable model for the disordered $\mathrm{MeOH}$ molecules. Thus the contribution of the disordered solvent to the diffraction pattern (36 molecules located in the voids of the channels of the lattice that amount to $25.0 \%$ of the unit cell) were subtracted from the observed data by the "SQUEEZE" method as implemented in PLATON. ${ }^{5}$

\footnotetext{
${ }^{2}$ SAINT, version 6.45, Bruker Analytical X-ray Systems, Madison, WI, 2003.

${ }^{3}$ Sheldrick G.M. SADABS Program for Absorption Correction, version 2.10, Analytical X-ray Systems, Madison, WI, 2003

4 (a) G. M. Sheldrick, Acta Cryst. 2008, A64, 112-122. (b) SHELXTL-2013/4, Bruker Analytical X-ray Instruments, Madison, WI, 2013.

${ }^{5}$ Spek, A. L. Acta Crystallogr. Sect. D, Biol. Crystallogr. 2009, 65, 148.
} 
The residual agreement factors for reflections with $I>2 \sigma(I)$ before SQUEEZE are R1 $=0.0664, \mathrm{wR} 2=0.1670$, and after $\mathrm{R} 1=0.0348, \mathrm{wR} 2=0.0977$. The final formulation of the compound is in agreement with the residual electron density and volume.

The final geometrical calculations on free voids and the graphical manipulations were carried out with PLATON ${ }^{5}$ implemented in WinGX, ${ }^{6}$ and CRYSTAL MAKER ${ }^{7}$ programs, respectively.

A summary of the crystallographic data and structure refinement for compound $\mathbf{1}$ is given in Table S1. CCDC reference number 1480930.

${ }^{6}$ Farrugia, L. J. J. Appl. Crystallogr. 1999, 32, 837.

${ }^{7}$ D. Palmer, CRYSTAL MAKER, Cambridge University Technical Services, C. No Title, 1996. 


\section{Table S1. Crystal data and structure refinement for 1.}

Empirical formula

Formula weight

Temperature

Wavelength

Crystal system

Space group

Unit cell dimensions

Volume

Z

Density (calculated)

Absorption coefficient

$\mathrm{F}(000)$

Crystal size

Theta range for data collection

Index ranges

Reflections collected

Independent reflections

Completeness to theta $=25.242^{\circ}$

Refinement method

Data / restraints / parameters

Final $\mathrm{R}$ indices $[\mathrm{I}>2 \operatorname{sigma}(\mathrm{I})]$

$\mathrm{R}$ indices (all data)

${ }^{c}$ Goodness-of-fit on $\mathrm{F}^{2}$

Absolute structure parameter

Largest diff. peak and hole

\section{C54 H96 Cr4 Mn3 N6 O54}

2066.18

296(2) K

$0.71073 \AA$

Trigonal

R 3 c

$\mathrm{a}=26.3296(16) \AA$

$\alpha=90^{\circ}$.

$\mathrm{b}=26.3296(16) \AA$

$\beta=90^{\circ}$.

$\mathrm{c}=23.314(3) \AA$

$\gamma=120^{\circ}$.

13997(2) $\AA^{3}$

6

$1.471 \mathrm{Mg} / \mathrm{m}^{3}$

$0.940 \mathrm{~mm}^{-1}$

6390

$0.22 \times 0.18 \times 0.18 \mathrm{~mm}^{3}$

1.547 to $22.321^{\circ}$.

$-28<=\mathrm{h}<=28,-28<=\mathrm{k}<=28,-24<=1<=24$

70469

$3985[\mathrm{R}($ int $)=0.0373]$

$71.0 \%$

Full-matrix least-squares on $\mathrm{F}^{2}$

3985 / 3 / 329

${ }^{a} \mathrm{R} 1=0.0348,{ }^{b} \mathrm{WR} 2=0.0977$

$\mathrm{R} 1=0.0367, w \mathrm{R} 2=0.0994$

1.036

0.01(3)

0.226 and -0.178 e. $\AA^{-3}$

${ }^{a} R_{1}=\sum\left(\left|F_{\mathrm{o}}\right|-\left|F_{\mathrm{c}}\right|\right) / \sum\left|F_{\mathrm{o}}\right| \cdot{ }^{b} w R_{2}=\left[\sum w\left(F_{\mathrm{o}}{ }^{2}-F_{\mathrm{c}}{ }^{2}\right)^{2} / \sum w\left(F_{\mathrm{o}}{ }^{2}\right)^{2}\right]^{1 / 2} \cdot{ }^{c} S=\left[\sum \mathrm{w}\left(\left|\mathrm{F}_{\mathrm{o}}\right|-\left|\mathrm{F}_{\mathrm{c}}\right|\right)^{2} /\left(N_{\mathrm{o}}-N_{\mathrm{p}}\right)\right]^{1 / 2}$. 


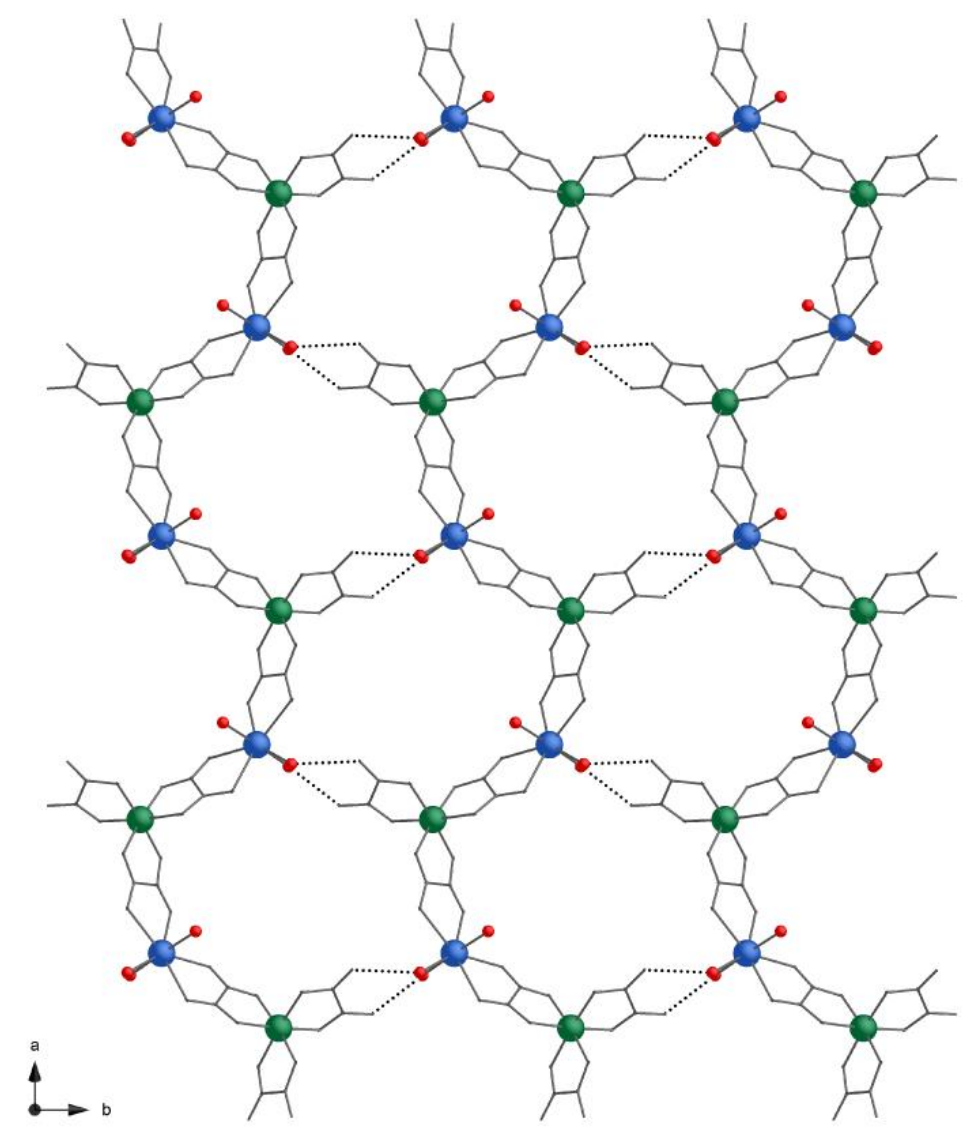

Figure S1. View of adjacent polymeric chains in the previously reported $\mathrm{N}\left(\mathrm{CH}_{3}\right)_{4}\left[\mathrm{Mn}\left(\mathrm{H}_{2} \mathrm{O}\right)_{3} \mathrm{Cr}(\mathrm{ox})_{3}\right] \cdot \mathrm{H}_{2} \mathrm{O} .{ }^{1}$ Metal and ligand atoms are represented by balls and sticks, respectively [Cr, green; $\mathrm{Mn}$, blue; $\mathrm{O}$ (water), red]. $\mathrm{N}\left(\mathrm{CH}_{3}\right)_{4}{ }^{+}$ cations and free water molecules are omitted for clarity. The dotted lines represent hydrogen bonds between oxalate oxygen atoms and coordinated water molecules of the neighboring chains. 


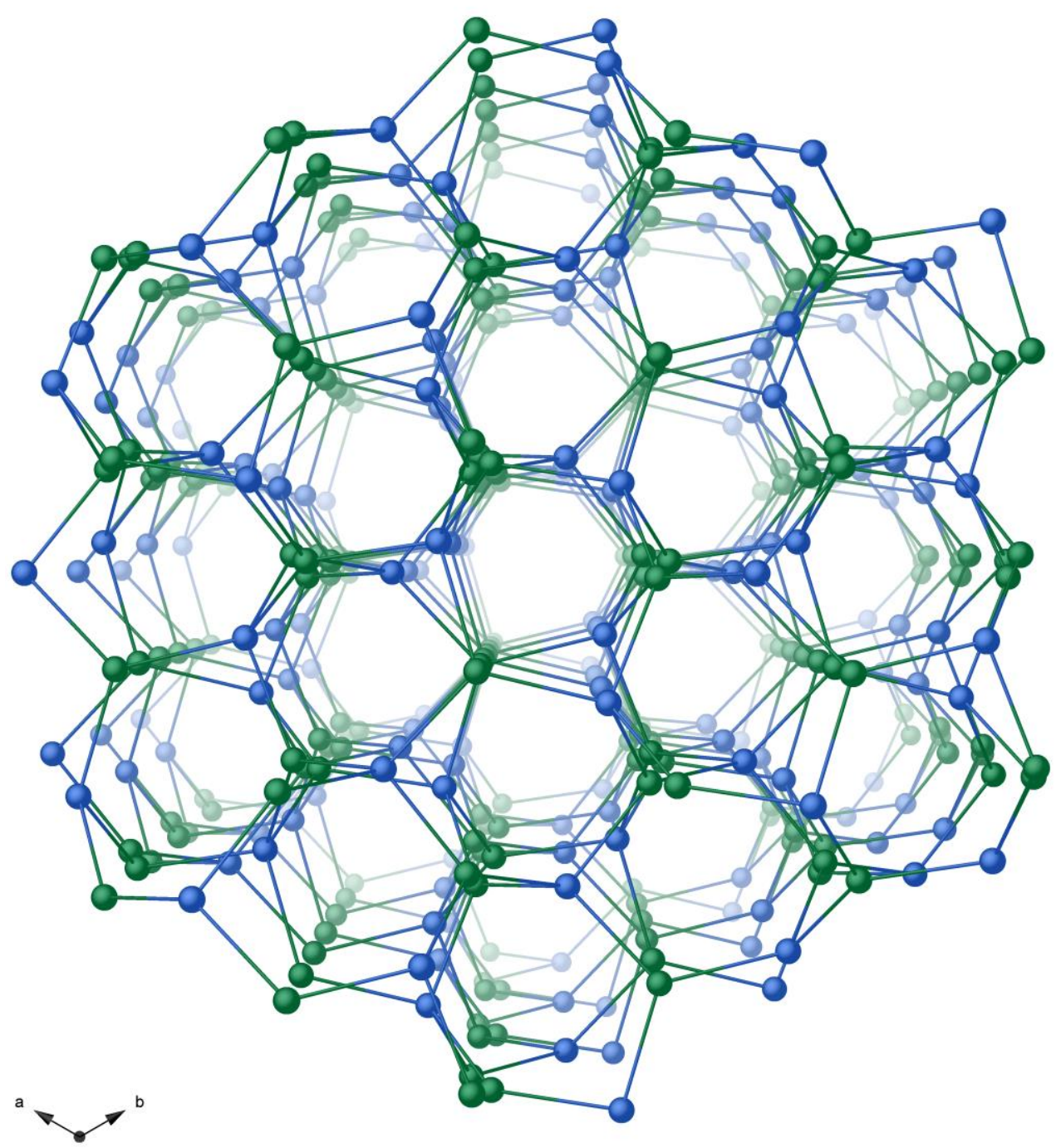

Figure S2. Schematic view illustrating the $\left(6^{3}\right)\left(6^{3} \cdot 8^{3}\right)$ topology of the binodal 3,4 net of compound 1. $\mathrm{Cr}$ and $\mathrm{Mn}$ atoms are represented as Green and blue spheres respectively. 


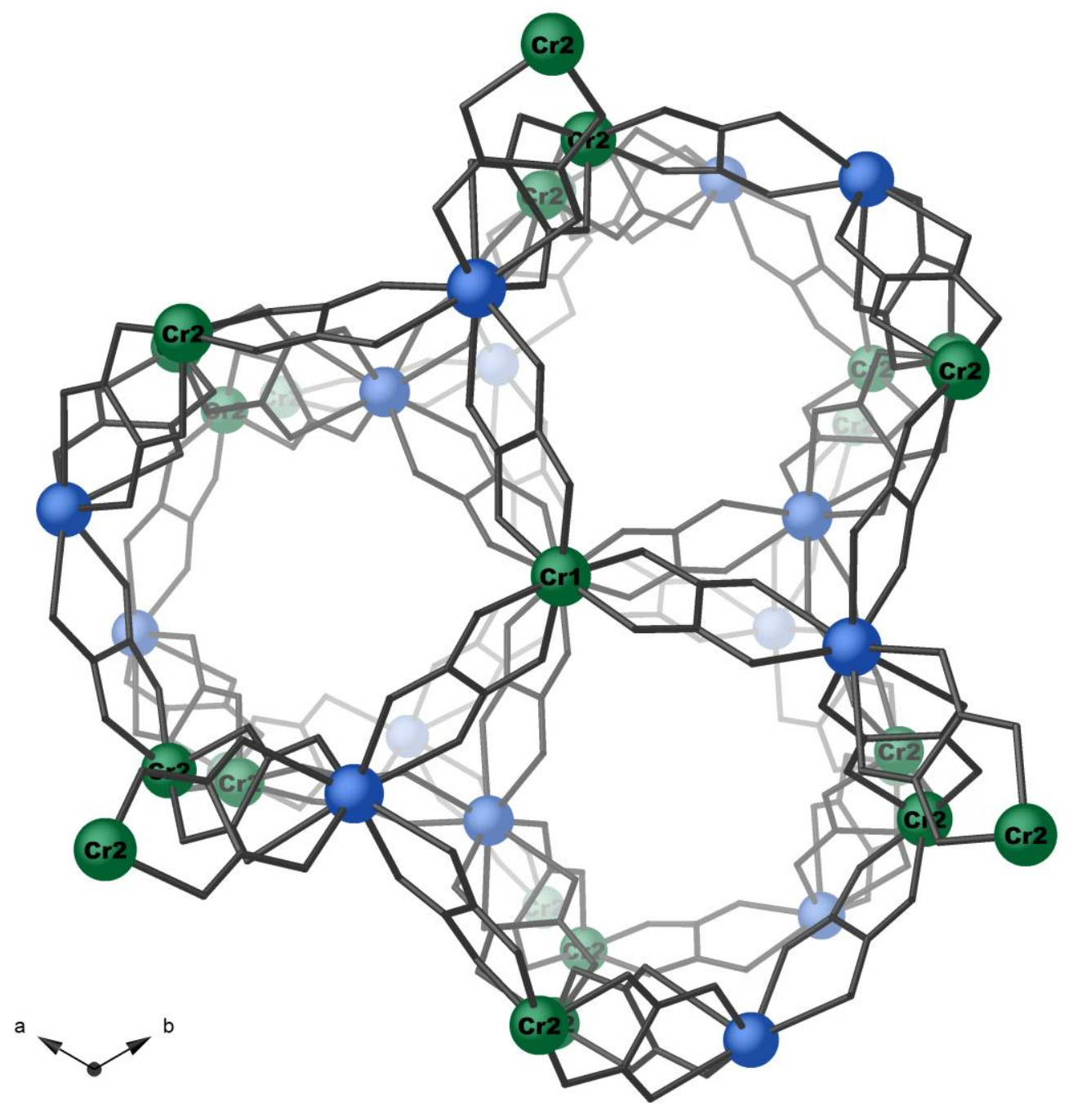

Figure S3. Details along $c$ axis of the binodal $(3,4)$ net with a $\left(6^{3}\right)\left(6^{3} \cdot 8^{3}\right)$ topology showing connectivities of both $\mathrm{Cr}^{\mathrm{III}}$ and $\mathrm{Mn}^{\mathrm{II}}$ ions acting as tri- and tetra-connectors in a threefold symmetry. $\mathrm{Cr}$ and $\mathrm{Mn}$ atoms are represented as Green and blue spheres respectively. 
a)

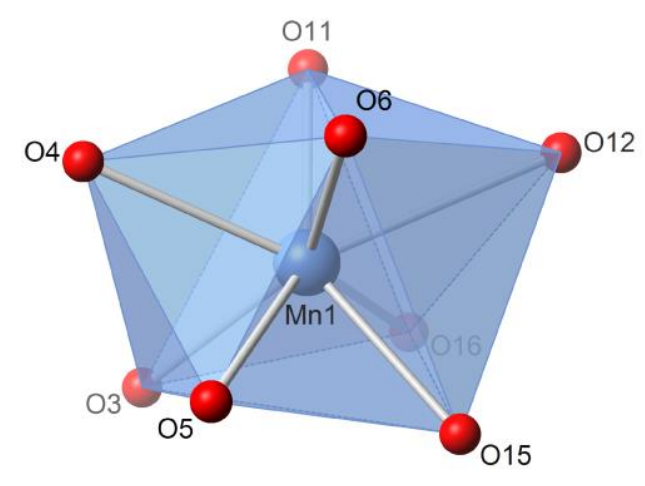

b)

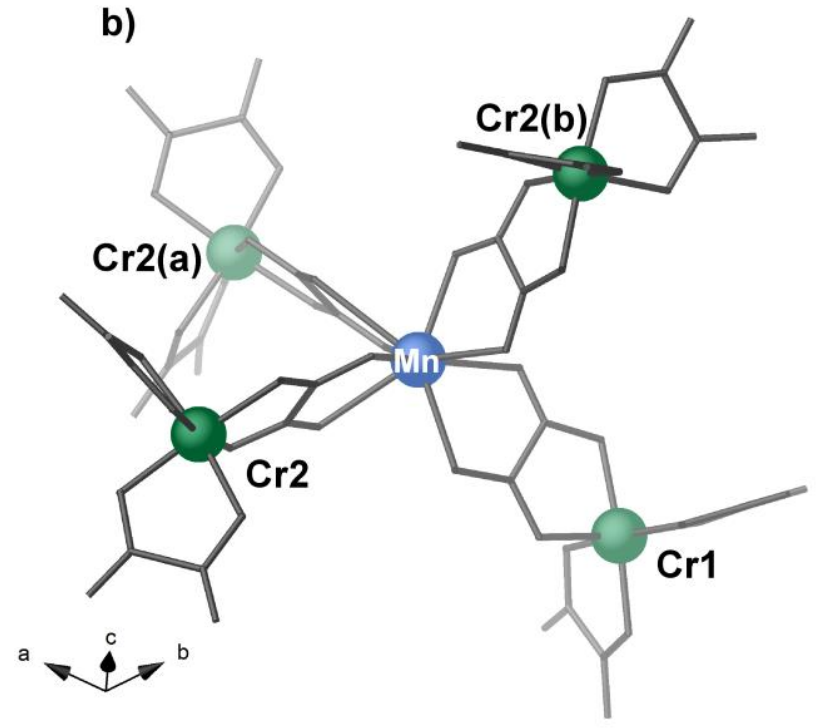

Figure S4. a) View of the $\mathrm{Mn}(\mathrm{II})$ coordination environment describing a distorted square antiprism; b) $\mathrm{Mn}(\mathrm{II})$ connectivity with four $\left[\mathrm{Cr}^{\mathrm{III}}(\mathrm{ox})_{3}\right]^{3-}$ ) entities through oxalate bridges giving four slightly different values of $\mathrm{Cr} \cdots \mathrm{Mn}$ separation through the oxalate bridge $[\mathrm{Cr}(1) \cdots \mathrm{Mn}=5.596(2), \mathrm{Cr}(2) \cdots \mathrm{Mn}=5.550(2), \mathrm{Cr}(2 \mathrm{a}) \cdots \mathrm{Mn}=5.674(2)$ and $\mathrm{Cr}(2 \mathrm{~b}) \cdots \mathrm{Mn}=5.572(2) \AA ;(\mathrm{a})=\mathrm{x}+1 / 3, \mathrm{x}-\mathrm{y}-1 / 3, \mathrm{z}+1 / 6 ;(\mathrm{b})=-\mathrm{y}+2 / 3,-\mathrm{x}+1 / 3, \mathrm{z}-1 / 6]$. 

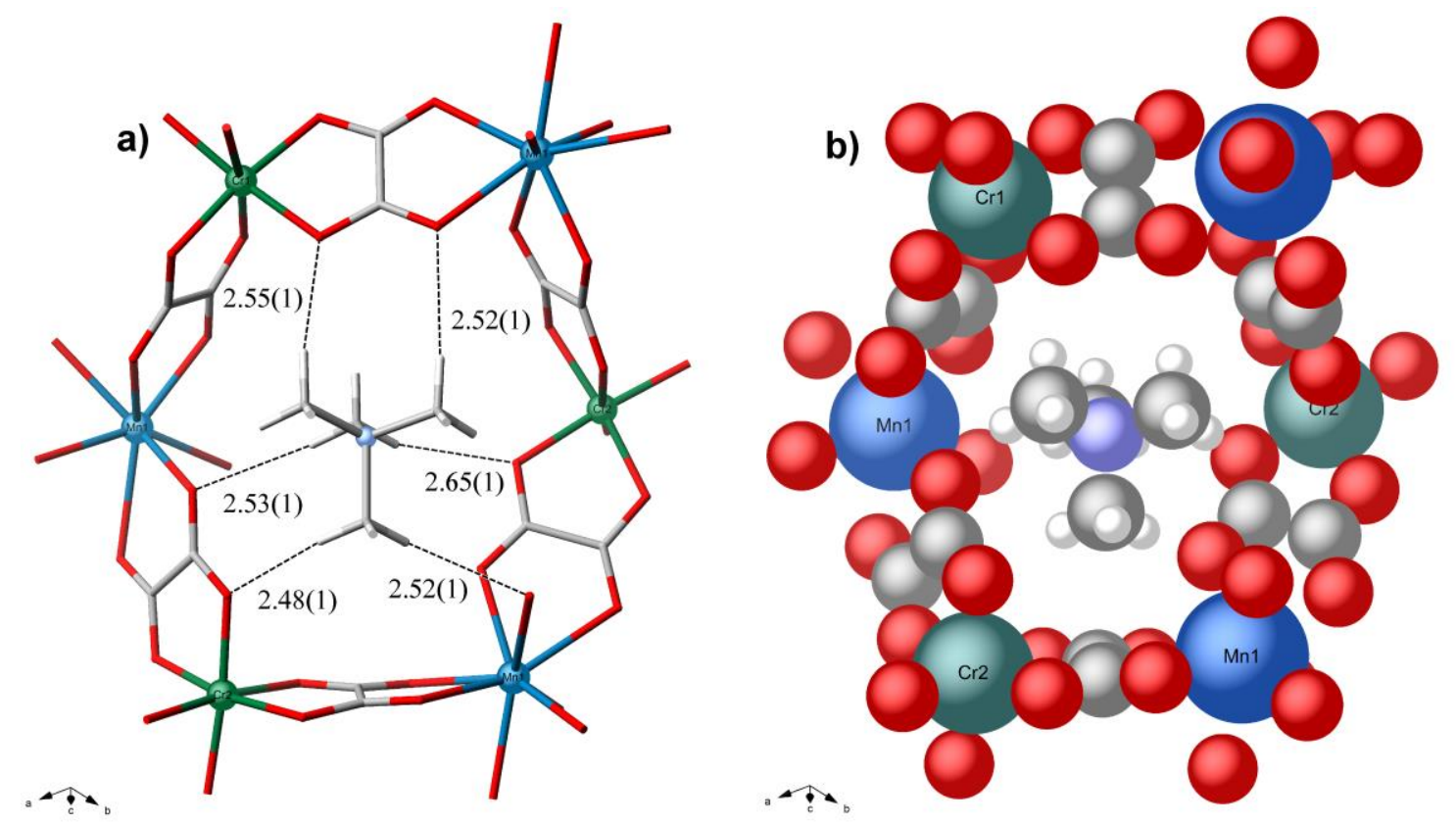

Figure S5. View as a) ball and sticks and b) space filling model of details of $\mathrm{H}-\mathrm{C} \cdots \mathrm{O}$ interactions involving $\left[\mathrm{N}\left(\mathrm{CH}_{3}\right)_{4}\right]^{+}$cations and the oxygen atoms of the oxalate ligands in a key and lock fashion. 


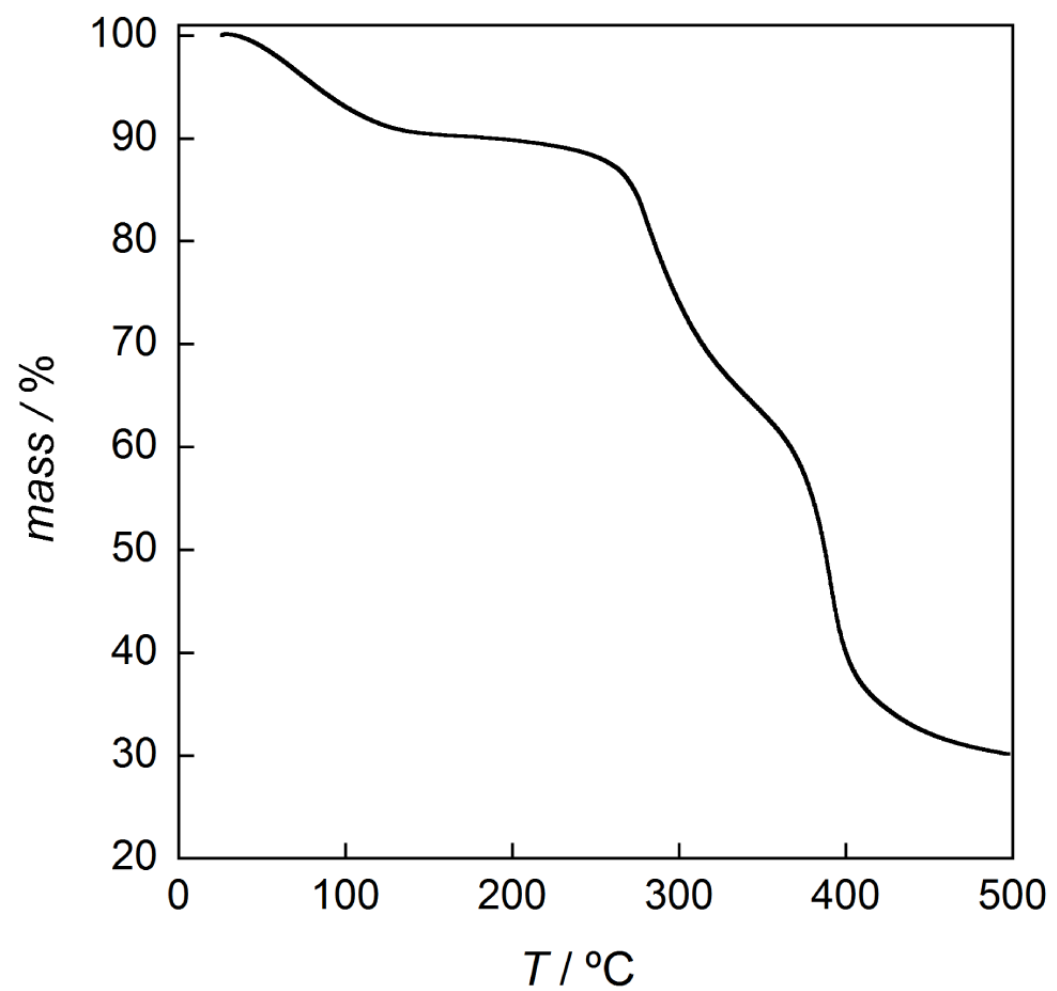

Figure S6. TGA of 1 under a dry $\mathrm{N}_{2}$ atmosphere. 


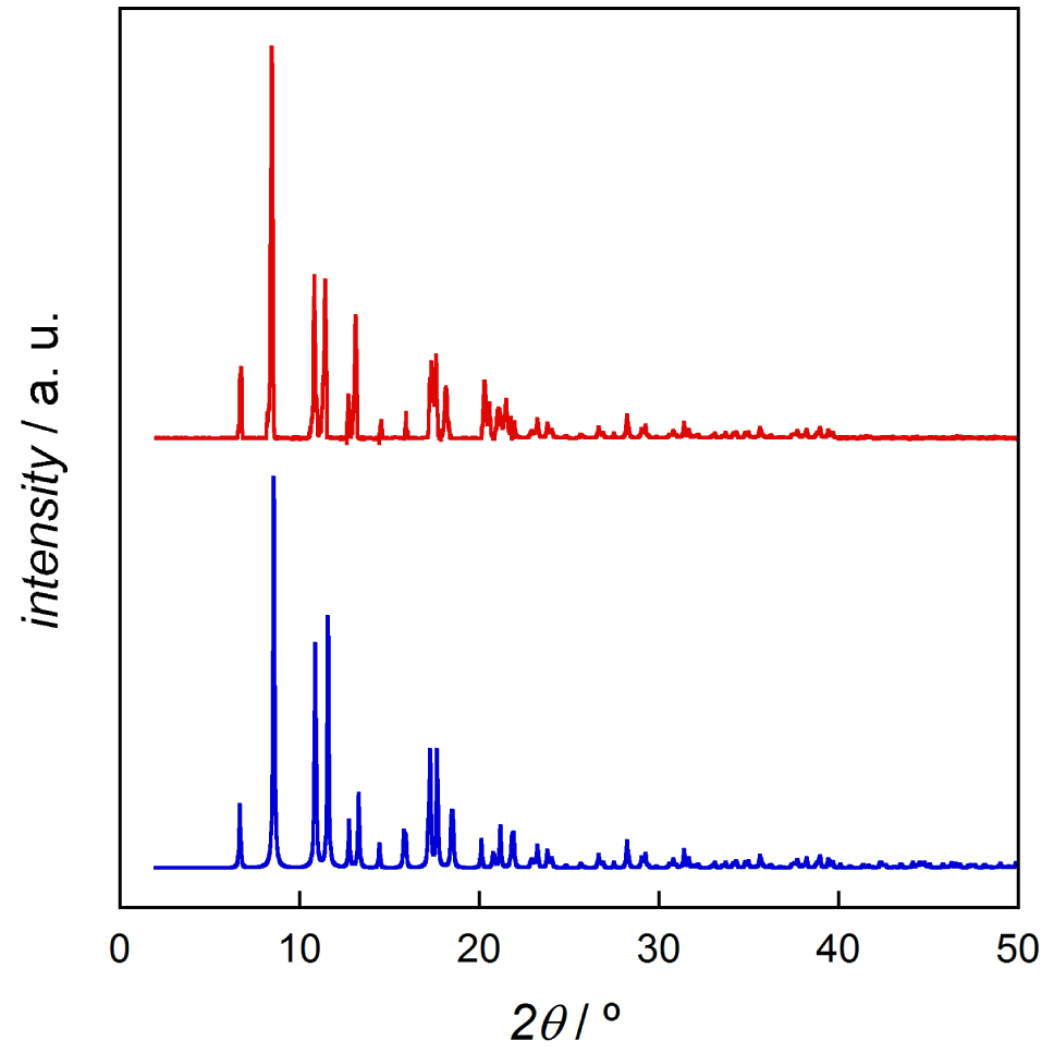

Figure S7. Experimental (red) and calculated (blue) PXRD pattern profiles of $\mathbf{1}$ in the $2 \theta$ range $2.0-50.0^{\circ}$ at room temperature. 